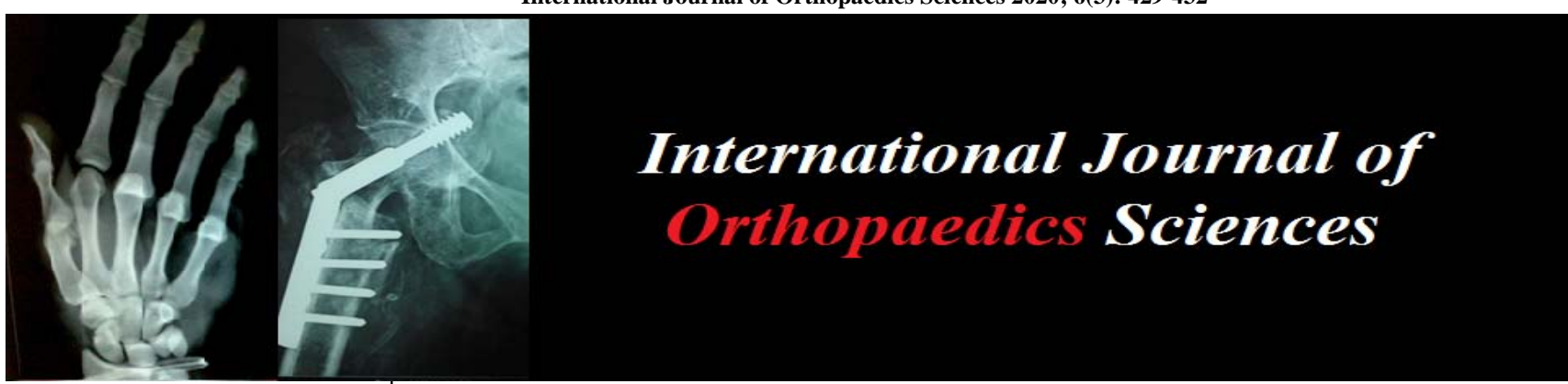

E-ISSN: 2395-1958

P-ISSN: 2706-6630

IJOS 2020; 6(3): 429-432

(C) 2020 IJOS

www.orthopaper.com

Received: 19-05-2020

Accepted: 21-06-2020

Dr. Rajesh Kishan Ambulgekar Professor and Head, Department of Orthopedics, Dr. S.C. Govt. Medical College, Vishnupuri, Nanded, Maharashtra, India

Dr. Vishal Ramesh Shewale Junior Resident, Department of Orthopedics, Dr. S.C. Govt. Medical College, Vishnupuri, Nanded, Maharashtra, India

Corresponding Author: Dr. Vishal Ramesh Shewale Junior Resident, Department of Orthopedics, Dr. S.C. Govt. Medical College, Vishnupuri, Nanded, Maharashtra, India

\section{Study of the functional outcome of unstable and displaced proximal humerus fracture in elderly treated with closed reduction and multiple percutaneous $K$ wire fixation}

\author{
Dr. Rajesh Kishan Ambulgekar and Dr. Vishal Ramesh Shewale \\ DOI: https://doi.org/10.22271/ortho.2020.v6.i3g.2234
}

\section{Abstract}

Background: Proximal humeral fractures are responsible for approximately five percent of all the fractures. It is difficult to attain a good anatomical reduction by closed reduction and may lead to possible complication of developing pseudoarthrosis at a very alarming rate.

Aims and objectives: 1 . To study the functional outcome of displaced and unstable proximal humerus fractures treated with closed reduction with multiple percutaneous $\mathrm{k}$ wire fixation.

2. To evaluate the complications of this modality.

Materials and Methods: The study is a prospective observational study. 33 patients with displaced and unstable proximal humerus fractures in elderly $>55$ years with closed proximal humerus fractures and medically fit for surgery were included in the study. After operation, the outcome of this modality was assessed by applying Constant Shoulder Scoring System.

Results: In most of the patients, flexion was 80 to 110 degrees, and abduction was 80 to 120 degrees. ER and IR points in most of the patients was more than 6 degrees. Most of the patients were having VAS scale 6 - 10 was seen in 14 cases (51.85\%) followed by VAS score of $0-5$ was seen in 10 cases (37.03\%) and VAS score of 11-15 was seen in 3 cases $11.11 \%)$. Most of the cases, 10 (37.03\%) cases were showing excellent results (Score 86-100). Pin track infection was seen in 3 (6.25\%) cases and k wire migration 2 cases $(9.38 \%)$

Conclusion: Multiple percutaneous k wire fixation is good option in an unstable and displaced proximal humerus fracture.

Keywords: Proximal humeral fractures, closed reduction, constant shoulder scoring system

\section{Introduction}

The proximal humeral fractures are responsible for approximately five percent of all the fractures that take place and among them most often the fractures occur in the aged people whose bones are osteoporotic ${ }^{[1]}$. In the proximal humerus fracture, it is difficult to attain a good anatomical reduction by closed reduction and this has the possible complication of developing pseudoarthrosis at a very alarming rate ${ }^{[2,3]}$

The closed proximal humeral fractures have been treated with a wide range of options, namely non-operative, open reduction internal fixation, external fixation, closed K-wire fixation, percutaneous screw fixation, and tension band fixation. Each procedure is having some limitations and complications ${ }^{[4,5]}$. Extensive exposure and the insertion of implants increase the risk of the development of AVN therefore limited exposure and dissection of the soft tissues at the fracture site with minimal internal fixation have been recommended ${ }^{[6]}$.

The data that is available in literature suggests that for the management of proximal humerus fracture by closed reduction with multiple percutaneous $\mathrm{k}$ wire fixation results in reduction in the degree of post-operative stiffness, minimal intra-operative blood loss, less soft tissue stripping and furthermore, the percutaneous $\mathrm{k}$ wires are easily removed after few weeks thus no metalwork remains in the proximal humerus.

In view of all this said in the above, we conducted a study to evaluate the method of closed reduction and stabilization of displaced and unstable proximal humerus fracture with multiple percutaneous $\mathrm{k}$ wire is done under image intensifier. 


\section{Aims and Objectives}

1. To study the functional outcome of displaced and unstable proximal humerus fractures treated with closed reduction with multiple percutaneous $\mathrm{k}$ wire fixation.

2. To evaluate the complications of this modality.

\section{Materials and Methods}

The study is a prospective observational study. After obtaining informed consent, 33 patients with displaced and unstable proximal humerus fractures in elderly $>55$ years with closed proximal humerus fractures and medically fit for surgery were included in the study. Patients having fractures due to Malignancy, Open fracture, Medical contraindication to surgery, Patient less than 55 years of age and with distal neurovascular deficit were excluded.

Anteroposterior and axial radiographs were taken to assess the type and severity of affected shoulder joint and type of fracture is classified by NEER's classification. Accordingly, patient was prepared for the surgery. Every patient was operated as early as possible or within 2 weeks of injury depending upon local condition of skin, vitals and anesthetic fitness of the patients. The outcome of this modality was assessed by applying CONSTANT SHOULDER SCORING SYSTEM.

\section{Observations and Results}

In the present study, most of the patients, 18 cases (54.54\%), were in age group 51-60 years, 7 cases (21.21\%) were in the age group 61-70 years, 4 cases (12.12\%) were in the age group $71-80$ years and $>80$ years each. $16(48.48 \%)$ were males and 17 (51.51\%) were females. The mode of injury was self-fall in 25 cases (75.75\%), RTA in 7 cases (21.21\%) and electrocution in only 1 case (3.03\%). 2 parts type of fracture in 5 cases (15.15\%), 3 parts type of fracture in 22 cases (66.66\%), 4 parts type of fracture in 6 cases (18.18\%).

\section{Functional Outcome}

Table 1: Flexion and Abduction

\begin{tabular}{|c|c|c|c|c|c|}
\hline \multirow{2}{*}{ Angles } & \multicolumn{2}{|c|}{ Flexion } & \multirow{2}{*}{ Angles } & \multicolumn{2}{c|}{ Abduction } \\
\cline { 2 - 3 } \cline { 5 - 6 } & No. of Patients & Percentage & & No. of Patients & Percentage \\
\hline 80 degrees & 5 & $18.51 \%$ & 70 degree & 3 & $11.11 \%$ \\
\hline 90 degrees & 1 & $3.70 \%$ & 80 degree & 2 & $07.40 \%$ \\
\hline 100 degrees & 2 & $7.40 \%$ & 90 degree & 6 & $22.22 \%$ \\
\hline 110 degrees & 2 & $7.40 \%$ & 100 degree & 6 & $22.22 \%$ \\
\hline 120 degrees & 0 & $00.00 \%$ & 110 degree & 1 & $03.70 \%$ \\
\hline 130 degrees & 4 & $14.81 \%$ & 120 degree & 4 & $14.81 \%$ \\
\hline 140 degrees & 2 & $7.40 \%$ & 130 degree & 0 & $00.00 \%$ \\
\hline 150 degrees & 2 & $7.40 \%$ & 140 degree & 0 & $00.00 \%$ \\
\hline 160 degrees & 7 & $25.92 \%$ & 150 degree & 4 & $14.81 \%$ \\
\hline 170 degrees & 2 & $7.40 \%$ & 160 degree & 0 & $00.00 \%$ \\
\hline TOTAL & 27 & $100.00 \%$ & 170 degree & 1 & $03.70 \%$ \\
\hline & & & Total & 27 & $100.00 \%$ \\
\hline
\end{tabular}

Table 2: ER and IR Points

\begin{tabular}{|c|c|c|c|c|}
\hline \multirow{2}{*}{ Angles } & \multicolumn{2}{|c|}{ ER-Points } & \multicolumn{2}{c|}{ IR-Points } \\
\cline { 2 - 5 } & Frequency & Percentage & Frequency & Percentage \\
\hline 4 degrees & 2 & $07.40 \%$ & 3 & $11.11 \%$ \\
\hline 6 degrees & 7 & $25.92 \%$ & 7 & $25.92 \%$ \\
\hline 8 degrees & 11 & $40.74 \%$ & 12 & $44.44 \%$ \\
\hline 10 degrees & 7 & $25.92 \%$ & 5 & $18.51 \%$ \\
\hline TOTAL & 27 & $100.00 \%$ & 27 & $100.00 \%$ \\
\hline
\end{tabular}

Table 1 shows in most of the patients, flexion was 80 to 110 degrees, and abduction was 70 to 160 degrees. ER and IR

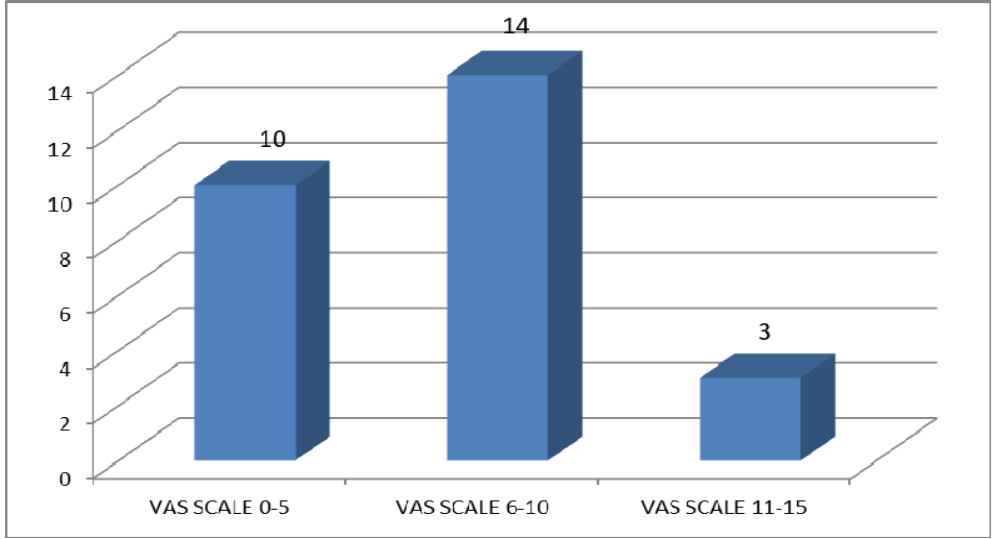

Graph 1: PAIN 
The above graph shows the degree of pain following treatment of the cases in the study. Most of the patients were having VAS scale 6-10 was seen in 14 cases (51.85\%) followed by VAS score of $0-5$ was seen in 10 cases (37.03\%) and VAS score of $11-15$ was seen in 3 cases $11.11 \%$ ).

Table 3: Activities of Daily Living

\begin{tabular}{|c|c|c|}
\hline Score & Number of Patients & Percentage \\
\hline Score 5 & 1 & $03.70 \%$ \\
\hline Score 7 & 2 & $07.40 \%$ \\
\hline Score 8 & 2 & $07.40 \%$ \\
\hline Score 9 & 2 & $07.40 \%$ \\
\hline Score 12 & 2 & $07.40 \%$ \\
\hline Score 13 & 3 & $11.11 \%$ \\
\hline Score 14 & 1 & $03.70 \%$ \\
\hline Score 15 & 2 & $07.40 \%$ \\
\hline Score 16 & 2 & $07.40 \%$ \\
\hline Score 17 & 3 & $11.11 \%$ \\
\hline Score 18 & 3 & $11.11 \%$ \\
\hline Score 19 & 2 & $07.40 \%$ \\
\hline Score 20 & 3 & $11.11 \%$ \\
\hline Total & 27 & $100.00 \%$ \\
\hline
\end{tabular}

The above graph and table show the activities of daily living following treatment of the cases in the study.

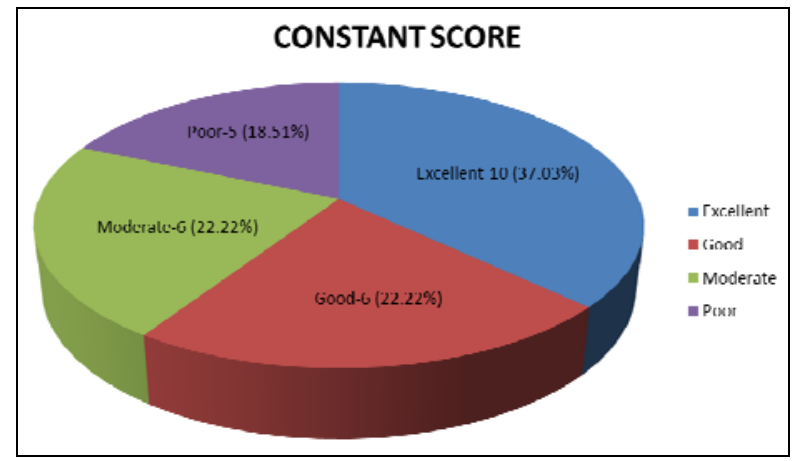

Graph 2: Constant Score

We had Excellent results (constant score >86) in 10 (37.03\%) cases, Good results (Score 71-85) in 6 (22.22\%) cases, Moderate results (Score 56-70) in 6 cases (22.22\%), Poor results (Score $<55)$ in 5 cases $(18.51 \%)$.

\section{Complications}

We had pin track infection in 3 (6.25\%) cases and $\mathrm{k}$ wire migration 2 cases $(9.38 \%)$

\section{Discussion}

Proximal humeral fractures occurring in elderly population are mostly displaced and unstable because of osteoporotic bones in elderly ${ }^{[3]}$. There are number of treatment options available for the management of proximal humeral fractures that range from the conservative methods like universal thoracohumeral immobilizer and strapping to the sophisticated surgical options like fixation with advanced plates and screws ${ }^{[4,5]}$.

A disadvantage of open reduction internal fixation is difficulty in achieving rigid fixation in the osteoporotic cancellous bone of proximal humerus. Cancellous bone in osteoporosis constitutes only a thin shell of bone and provides weak purchase for the screws ${ }^{[6,9]}$.

Percutaneous fixation has been reported in few papers as viable option, due to important limitations as long time of recovery, high rate of pins infection, poor reduction of fragments particularly in bone fragility ${ }^{[10,11]}$

However, the advantage of this technique is its minimal invasive, less blood loss, less exposure and soft tissues stripping and usefulness in older patients ${ }^{[12,13]}$ Use of smooth K-wires predisposes to pin loosening and loss of reduction: drilled K- wires with threaded tips allow reduction of this complication. Other advantage of percutaneous fixation is that in case of early loss of reduction ORIF may be performed ${ }^{[7,8]}$.

\section{Complications}

We had pin track infection in 3 cases and $\mathrm{k}$ wire migration 2 cases. Chandan Kumar et al. ${ }^{[14]}$ encountered in this series were Varus mal-reduction in $17 \%(n=7)$, screw perforation in $10 \%(n=4)$, plate impingement in $12 \%(n=5)$, infection in $2 \%(n=1)$, and nonunion in $2 \%(n=1)$ of cases.

Akshat Vijay et al. ${ }^{[15]}$ had 17 complications (K-wire migration-2, infection- 2, malunion-4, stiff shoulder-6, and pain in shoulder-3) were seen in 10 patients $(41.1 \%)$ fixed with K-wire.

\section{Constant Score}

Chandan Kumar et al. ${ }^{[15]}$ had Constant scores for 2-part (79.83 \pm 6.95) and 3-part fractures (74.22 \pm 12.53) were significantly superior to those of 4 - part fractures (61.09 \pm 14.29) We had Excellent results in 5 cases $15.15 \%$, Good results in 4 cases $12.12 \%$, Medium results in 11 cases $33.33 \%$, Poor results in 7 cases $21.21 \%$.

\section{Conclusion}

Multiple percutaneous $\mathrm{k}$ wire fixation is a better option for patients having unstable and displaced proximal humerus fracture. Key to success are careful reduction to restore the anatomy, a biomechanically sound pin configuration to maximize fixation, appropriate aftercare to achieve healing. Advantages of this technique is its minimal invasive, less blood loss, less exposure and soft tissues stripping and usefulness in elderly patients. Furthermore, the percutaneous pins are easily removed after few weeks thus no metalwork remains in the proximal humerus.

\section{Reference}

1. Palvanen M, Kannus P, Niemi S, Parkkari J. Update in the epidemiology of proximal humeral fractures. Clinical Orthopaedics and Related Research (1976-2007). 2006; 442:87-92.

2. Court-Brown CM, Garg A, McQueen MM. The epidemiology of proximal humeral fractures. Acta orthopaedica Scandinavica. 2001; 72(4):365-371.

3. Szyszkowitz R, Seggl WO, Schleifer PE, Cundy PJ. Proximal humeral fractures. Management techniques and expected results. Clinical orthopaedics and related research. 1993; (292):13-25.

4. Hanson B, Neidenbach P, de Boer P, Stengel D. Functional outcomes after nonoperative management of fractures of the proximal humerus. Journal of Shoulder and Elbow Surgery. 2009; 18(4):612-621.

5. Tejwani NC, Liporace F, Walsh M, France MA, Zuckerman JD, Egol KA. Functional outcome following one-part proximal humeral fractures: a prospective study. Journal of shoulder and elbow surgery. 2008; 17(2):216219.

6. Wijgman AJ, Roolker W, Patt TW, Raaymakers EL, Marti RK. Open reduction and internal fixation of three and four-part fractures of the proximal part of the 
humerus. JBJS. 2002; 84(11):1919-1925.

7. Brunner F, Sommer C, Bahrs C, Heuwinkel R, Hafner C, Rillmann $\mathrm{P}$ et al. Open reduction and internal fixation of proximal humerus fractures using a proximal humeral locked plate: a prospective multicenter analysis. Journal of orthopaedic trauma. 2009; 23(3):163-172.

8. Koval KJ, Gallagher MA, Marsicano JG, Cuomo F, McShinawy A, Zuckerman JD. Functional outcome after minimally displaced fractures of the proximal part of the humerus. JBJS. 1997; 79(2):203-207.

9. Ko JY, Yamamoto R. Surgical treatment of complex fracture of the proximal humerus. Clinical Orthopaedics and Related Research®. 1996; 327:225-237.

10. Laing PG. The arterial supply of the adult humerus. JBJS. 1956; 38(5):1105-1116.

11. Duparc F, Muller JM, Frçger P. Arterial blood supply of the proximal humeral epiphysis. Surgical and Radiologic Anatomy. 2001; 23(3):185-190.

12. Keener JD, Parsons BO, Flatow EL, Rogers K, Williams GR, Galatz LM. Outcomes after percutaneous reduction and fixation of proximal humeral fractures. Journal of shoulder and elbow surgery. 2007; 16(3):330- 338.

13. Gerber C, Schneeberger AG, Vinh TS. The arterial vascularization of the humeral head. An anatomical study. J Bone Joint Surg Am. 1990; 72(10):1486-1494.

14. Kumar C, Gupta AK, Nath R, Ahmad J. Open reduction and locking plate fixation of displaced proximal humerus fractures. Indian journal of orthopaedics. 2013; 47(2):156.

15. Vijay A, Kumar M, Bhaskar SK, Rao BS, Gandhi M. Comparison of open reduction internal fixation with proximal humerus interlocking system and close reduction and pinning with K-wire in proximal humeral fracture. J Orthop Traumatol Rehabil. 2017; 9:99-105. 